Francisco Delicado, La Lozana Andaluza, 1528 (ed. Madrid, 1916, pág. 80), incluye a estas viejas en su famoso catálogo.

Vejez y alcahuetería andaban juntas en las proxenetas; y sin duda las experiencias de un liviano contribuyeron al hondo saber que todos los personajes de la Tragicomedia reconocen en Celestina. Sólo así podrán acabar de explicarse satisfactoriamente las artes de tercería en que no tienen igual "estas viejas troyas" del Arcipreste ${ }^{20}$.

University of Pennsylvania.

Carlos Clavería

\title{
-L Y -R IMPLOSIVAS EN EL ESPAÑOL DE PANAMÁ
}

En Geografía fonética: -1 y -r implosivas en español (RFH, viI, 4, págs. 313-345) Amado Alonso y Raimundo Lida han estudiado el fenómeno de $-l$ y $-r$ implosivas, presentando también una extensa descripción de la geografía del fenómeno, tanto en España como en América.

Sus datos indican que en España la confusión de $-r$ y $-l$ se encuentra en el Ebro medio, en la Extremadura leonesa, en la Mancha, en Murcia y en distintas zonas de Andalucía. Su geografía en América es extensa. Existe en el centro de Chile, en la región argentina de Neuquén, en Cuba, Santo Domingo, Puerto Rico, Panamá, Colombia, Venezuela, en la costa del Ecuador y del Perú y tal vez en la costa mexicana del Golfo. Las alteraciones articulatorias que citan demuestran que en fin de sílaba $l$ y $r$ pierden dialectalmente su dualidad y oposición y son manifestaciones de un hecho general: la degradación o relajación de las consonantes en final de sílaba (pág. 342).

He podido ahora conseguir datos más extensos sobre la pronunciación de $-l$ y $-r$ en el habla de Panamá. Casi todos los casos mencionados a continuación fueron oídos personalmente en las provincias centrales de la República de Panamá o sean las de Coclé, Herrera, Los Santos y Veraguas. Estas cuatro provincias tienen una población de unos 230,000 habitantes, de sangre mestiza y blanca en la mayor parte. La poca sangre negra que existe data de la época colonial. La cultura de esta región es netamente rural, lo cual se refleja claramente en su habla.

Ante $l$, la $r$ se aspira entre campesinos: buhld, Cahlos, y en la $r$ de los infinitivos ante pronombre enclítico: bañahlo, tenehlo, comehlo, velahlo; estos cuatro últimos ejemplos aparecen también entre personas del pueblo. No hay aquí casos de metátesis ni de palatalización de -rl- en - $l l$ - Tampoco hay casos de sustitución de $r$ por $s$. El único ejemplo recogido, El Irlandés $>$ El Islandés (nombre de un campo de la provincia de Veraguas) es de dudoso valor debido a la probable confusión de Irlanda con Islandia.

En el grupo -rn- la $r$ se aspira, con sonido semejante al de $s$ aspirada ante $p$, $t, k$ pero con un pequeño aumento de intensidad: piehna, cahne, inviehno, tehnero, Hehnández, bochohno, Behnardina, gahnucho, Gahnadera (nombre de un campo de Veraguas), con ejemplos de Coclé, Los Santos y Veraguas. Ésta es la pronuncia-

20 Después de redactado este estudio he podido consultar en R. S. Boggs, LL. Kasten, H. KenisTON, H. B. Richardson, Tentative dictionary of medieval Spanish, II, Chapel Hill, 1946, pág. 510, la interpretación de la palabra del Arcipreste: troya 'mujeres arrugadas o alcahuetas?'. También compruebo en el Vocabulario de germanía de Hidalgo (véase la reproducción de la primera edición en Poesías germanescas edited by J. M. Hill, Bloomington, pág. 115) la significación de grofa 'muger publica, baxa'. R. Salinias, El delincuente español, pág. 290, y A. Niceroro, Le génie de l'argot, $2^{\text {a }}$ ed., Paris, 1912, pág. 118, observan que la etimología de esa palabra es lat. scrofa, 'puerca', 'truie'. 
ción usual entre campesinos. Tal aspiración no llega a ser una asibilación de la $r$ como la notada por Henríquez Ureña en Santo Domingo ${ }^{1}$. No hay casos de $-r n->-r r-$ fuera de garniel>carriel; sí hay un ejemplo del cambio contrario, bodohnio < bodorrio, término usado por los campesinos del sur de Veraguas. Pero estos dos cambios tienen sin duda alguna complicación extrafonética.

En el grupo -rl- la aspiración de la $r$ puede oírse hasta entre la clase media de los pueblos, y tal articulación no se repudia. Sin ennbargo, en el grupo -rn- la aspiración se oye solamente en el habla rural y los de la clase media usan esta articulación sólo cuando quieren remedar el modo de hablar de los campesinos.

En las combinaciones -rt-, $-r d$ - la $r$ se asimila al sonido que sigue, dando como resultado una $t$ o $d$ alargadas, como las que describe Lenz en el habla de Chile ${ }^{2}$. En tal caso la articulación resultante es dental y la $t$ o $d$ se pronuncian con más intensidad que de ordinario. Lenz las escribe fonéticamente tt $\mathrm{y} d$ :. Las formas siguientes son de las provincias centrales: puetta, muette, recued:o, ved:e, pied:a, tad:e. Esta asimilación de la $r$ a una $t$ o d siguientes es corriente en el sur de Veraguas y en Herrera, sobre todo entre habitantes de Chitré y Pesé. Hay también ejemplos de la provincia de Los Santos, pero en Coclé es menos frecuente, pues allí es mayor la tendencia a la pronunciación mixta de la $r$. En esta pronunciación la $r$ tiene acústicamente rasgos de $r$ y $l$ a la vez, así: pé $[r l] d i d a^{*}$, conso[rl]te, fue $[r l] t e$, sace $[r l]$ dote. Del extremo oriente de la Intendencia de San Blas, Panamá, son los ejemplos cuatto, cueppo, oídos a negros colombianos de las costas del departamento de Bolívar y la Intendencia del Chocó.

Ante otras consonantes la $r$ puede sonar en las provincias centrales con la pronunciación mixta de $r$ y $l$ : cá $[r l]$ cel, dive $[r l]$ sión, $t u[r l] c o, b a[r l] b e r i ́ a, p o[r l] q u e$.

En el caso de la $-l$ implosiva en interior de palabra cuando va seguida de dental existe una vacilación. O puede asimilarse, como sucede con la $-r$, así fad:a, uttrajado, o puede tener una pronunciación mixta, que es la que predomina: ma[rl]dició, revue $[r l] t a, a[r l] t a$, espa[rl]da, a[rl]tivo, vue $[r l] t a$. En otras combinaciones también predomina la articulación mixta: bo[rl]sillo, $p u[r l] g a, b o[r l] s a$. Aquí la pronunciación mixta ha ganado terreno a expensas de la tendencia asimilatoria.

Se dan alternancias como mercocha y melcocha, sarpuido y salpuido y hasta sampuido (Aguadulce, provincia de Coclé).

En Panamá no he recogido ejemplos de vocalización de $-l$ o $-r$ ni en interior ni en final de palabra. Hay algunas palabras en que se pierde una $-l$ interior: apargata, cuaquier, amorzar, pitrafa. De éstas, apargata, cuaquier y amorzar se oven también en otras regiones ${ }^{3}$.

Existen tres articulaciones de la $r$ en posición final ante pausa. La más frecuente es la mixta de $r$ y $l$ : di $[r l], m a[r l]$, ve[rl], luga[rl], colo[rl], mejo[rl], superio $[r l]$, entra $[r l]$. Estos ejemplos son de las cuatro provincias centrales. En Macaracas, provincia de Los Santos, he oído fad:a[rl] (Faldar, nombre de un campo), con asimilación de la -l-interior a la $d$ siguiente (de donde una articulación dental retrasada) y articulación mixta de la -r final.

Con menos frecuencia y sólo entre campesinos se oye una articulación nasalizada de la -r find. En este caso viene acompañada de una ligera nasalización de la vocal anterior. Entre los casos recogidos no hay ninguno en que esta vocal no sea $e$. La nasalización de la consonante final puede llegar casi hasta un sonido nasal velar:

$1 \mathrm{BDH}, \mathrm{iv}$, pág. 304.

$2 \mathrm{BDH}$, vr, págs. 114 y sig.

* [Por dificultades de imprenta, representamos aquí con [rl] el fonema intermedio entre $r$ y 1 .]

$3 \mathrm{BDH}$, I, págs. 234, nota. 
vamos vẽ español de las Antillas ${ }^{4}$. Esta articulación no es la misma del estado de Jalisco, México, pues allí se trata de la adición de un sonido nasal después de -s y -r en sílaba final acentuada 5 .

En su obra escrita hace unos treinta años, el Prof. Feliciano Quirós y Q. declara que la pérdida de la -r final se oía en el habla de Los Santos, Antón y la capitala. Según testimonio oral del Prof. Quirós, este fenómeno se oye hoy en las provincias centrales, pero donde tiene mayor frecuencia es en la capital. En las provincias centrales suele oírse solamente entre campesinos: señó, Vito (Víctor). A veces ocurre en palabras de origen inglés introducidas en el español de Panamá: bompe < bumper (para choques de automóvil), zipe<zipper (cierre automático de ropa). En los Cuentos panameños de la ciudad y del campo, Ignacio de J. Valdés, Jr., trae cuentos de la provincia de Veraguas con señó, tomá, Mano Sarvaót. He oído personalmente charlá, morí en Pito, Intendencia de San Blas, en el habla de negros de origen colombiano.

No suele añadirse una $e$ paragógica a una $-r$ final. Por lo menos no he recogido ejemplos. Sin embargo, testigos de la provincia de Veraguas han dicho que entre los indios de la montaña de esa provincia, recién incorporados a la cultura hispánica, se puede oír este fenómeno, dando como ejemplo calore.

En posición final ante pausa es más frecuente la pronunciación mixta de la $l$ : $c a[r l]$, rea $[r l]$, mie $[r l]$, fie $[r l]$. Moisés Castillo en Allá donde uno trae ño Manué, $R a f e ́<$ Rafael ${ }^{8}$. Esta pérdida de $-l$ final es de menos frecuencia que la de $-r$ en las provincias centrales.

Hay que notar que, con una sola excepción, estas alteraciones de $-r$ y $-l$ no se aceptan en el habla de la clase media del pueblo o de la ciudad. La aspiración de -r en la combinación -rl- es la única alteración interior de palabra admitida entre personas más o menos instruídas. Los cambios en final de palabra ante pausa son exclusivamente del habla rural y vulgar.

Al examinar las condiciones en que se encuentran $-l$ y $-r$ en el habla de esta región, se advierte que sólo hay dos combinaciones en que no existen casos de igualación en una articulación mixta que fonéticamente tiene algo de $r$ y algo de $l$ a la vez. Son las combinaciones -rl- y -rn-. En las demás condiciones en interior de palabra $-l$ y $-r$ pueden igualarse en la pronunciación mixta o las dos pueden asimilarse a una $t$ o $d$ siguientes, también igualándose. La asimilación no rige siempre ni con $-l$ ni con $-r$, pues aun seguidas de estos sonidos dentales pueden igualarse en la pronunciación mixta como sucede en la provincia de Coclé. En posición final absoluta predomina esta misma igualación ya descrita, aunque tanto $l$ como $r$ desaparecen en esta posición.

En general la consonante que sigue determina la articulación de la $-r$ interior de palabra. En las combinaciones -rl- y $-r n$ - se aspira la $r$ y casi no se admite otra articulación. Las dentales influyen más sobre $-r$ que $-l$, en Herrera y el sur de Veraguas sobre todo, aunque en otras partes, como se ha visto arriba, alterna la asimilación con la pronunciación mixta. De los datos recogidos se nota que sobre $-l$ no influyen consonantes siguientes que no sean $t$ o $d$.

4 Observaciones sobre el español en América, en RFE, viri, pág. 373.

5 L. O. Wright y S. L. Robe, Final consonant plus in Jalisco, Mexico, en MLN, LIV, págs. 439-42. pág. 8 .

6 El castellano de Panamá: Fonología. Tirada en mimeógrafo. Santiago de Veraguas, 1941,

7 Panamá, 1928, págs. 10, 20, 32.

8 Panamá, 1946, págs. $87,98$. 
También en posición final absoluta la igualación resulta de mayor fuerza en cuanto a la $-l$, pero para la $-r$ alternan tres soluciones: la igualación en una articulación mixta de $l$ y $r$, la desaparición y nasalización. Sólo esta última no aparece compartida por la $l$ final absoluta.

Los datos y las conclusiones dados aquí responden a la invitación de los señores Alonso y Lida en su citado artículo, y su fin es el de ampliar y fijar nuestro conocimiento del fenómeno en una región americana.

Universidad de North Carolina.

Stanley L. Robe

\section{ADICIÓN A SOY QUIEN SOY}

La señora E. G. Linfors-Nordin en su tratadito Berne... berner (Stockholm, 1948) habla, entre otras cosas, de la empresa heráldica de la casa reinante de Béarn que figura en las monedas de esa provincia, suprimidas en Francia por decreto del rey Francisco I, en 1532: "Écus, sols, deniers... porte-bonheur de l'incomparable devise seigneuriale de 'Berne', qui se lisait en bordure de leurs champs: Gratia Dei sum, id quod sum... furent envoyés au billon et fondus en 1532".

La señora Linfors-Nordin, consultada por mí, no pudo determinar la primera aparición de esta empresa, que me parece denotar el orgullo equilibrado de un ser medieval que acepta su posición como una gracia de Dios, manteniéndose en una aurea mediocritas, sin caer en la soberbia, pero con plena conciencia del propio valor, con esa actitud de "gradualismo" tan conocida de todos los medievistas. La diferencia con soy quien soy reside en que sum id quod sum se relaciona con el concepto (medieval) de ser algo (cf. Menéndez Pidal, glosario del Poema del Cid, s. v. algo), mientras que soy quien soy está en conexión con el (renacentista) ser alguien. Es difícil decidir dónde colocar el otro lema, más famoso, de la casa francesa de Rohan: Roy ne puis, prince ne daigne, Rohan suis: hay aquí cierta aceptación del "término medio", pero llena de orgullo nobiliario, y ya no se habla de la gracia de Dios. Sea como fuere, habría que estudiar los lemas heráldicos de la aristocracia española para ver si hay en ellos precedentes más convincentes de soy quien soy.

Leo Spitzer

The Johns Hopkins University.

\section{TIRSO Y EL ROMANCE DE ANGÉLICA Y MEDORO}

Poco estudiado está el teatro de Tirso en lo que respecta a sus fuentes ${ }^{1}$. En Quien habló, pagó, editada por Cotarelo y Mori, INBAE, IV, págs. 178-206, hay una escena donde es indudable la imitación del romance de Angélica y Medoro de Góngora. En la primera jornada, que es la que aquí nos interesa, los personajes principales son el conde de Urgel y la reina de Aragón. Creyendo ésta haber sido difamada por el conde, ordena su asesinato, que se lleva a cabo en un bosque, por

1 El único estudio extenso, de Pedro Muñoz Peña, El Teatro del Maestro Tirso de Molina, Valladolid, 1889 , es lo bastante voluminoso para ahuyentar al lector común y lo bastante malo para ahuyentar al erudito. 